\title{
PRODUCTION, LOSSES, AND GERMINATION OF CEANOTHUS FENDLERI SEEDS IN AN ARIZONA PONDEROSA PINE FOREST
}

\author{
David W. Huffman ${ }^{1}$
}

\begin{abstract}
Aвstract.-I quantified seed production and ovule losses for Ceanothus fendleri Gray (Fendler ceanothus) plants protected from large ungulate herbivores in a ponderosa pine (Pinus ponderosa [Laws]) forest of northern Arizona. I also tested seed germination responses to cold stratification and heat treatments in the laboratory. Fruit production on fecund stems ranged from 7.4 to 38.2 fruits per stem, which equated to 22.2-118.2 potential seeds based on 3 ovules per fruit. Stems that produced fruit were significantly large relative to their expected sizes. Predispersal ovule losses ranged from $70.7 \%$ to $91.4 \%$ across the 2 years studied. A chalcidoid seed parasite (Eurytoma squamosa Bugbee) consumed $11 \%-28 \%$ of the total number of seeds produced. Postdispersal seed predation varied from $0 \%$ to $24 \%$ and was significantly affected by forest floor substrate in 1 study year. Cumulative ovule losses were estimated to be $71 \%-92 \%$. Cold stratification did not significantly affect seed germination, and exposure to $90^{\circ} \mathrm{C}$ resulted in the highest germination percentage. Both dormant and nondormant seeds suggested a bet-hedging life history strategy. This study provides basic ecological information important for management of ponderosa pine forest and nursery production of $C$. fendleri.
\end{abstract}

Key words: Fendler ceanothus, seed ecology, ovule losses, seed predation, heat scarification, bet hedging.

For many forest plant species, basic data on the ecology of seed populations are incomplete. However, these data may have many important applications. For example, information about seed production and inputs to soil seed banks can assist land stewards as they formulate plans for vegetation management activities such as site rehabilitation, ecological restoration, or weed control. Data on seed parasitism and predation can help scientists to model food web interactions or long-term plant population growth. Finally, horticulturists need information regarding germination of desirable species and factors that affect seed viability.

Ceanothus fendleri Gray (Fendler ceanothus) is a small shrub common in ponderosa pine (Pinus ponderosa) forests of the southwestern United States and Rocky Mountains (Epple 1995). Like its congeners, C. fendleri is a nitrogen-fixer (Story 1974, Conard et al. 1985) and provides important functional and structural qualities in understory communities. It is particularly valuable as wildlife browse, although intensive herbivory by native ungulates such as mule deer (Odocoileus hemionus) and Rocky Mountain elk (Cervus elaphus) can reduce stem length, leaf area, and flower production (Huffman and Moore 2003). Clusters of white flowers appear in early spring and provide an important resource for invertebrates. Constraints on flower production resulting from intensive herbivory indirectly affect abundance and richness of invertebrate assemblages (Huffman unpublished data). In the absence of herbivory, flower production can be prolific, and this lends an ornamental quality desirable for urban landscaping.

C. fendleri fruits are 3-celled capsules that ripen August-September (Kearney and Peebles 1964). Seeds are dark brown and about $2 \mathrm{~mm}$ in diameter. Limited data suggest that Fendler ceanothus seeds have some level of innate dormancy (Story 1974, Krishnan 1989). Observations of seedling emergence after prescribed fire suggest that dormant seeds remain viable in soil seed pools until scarified by heat or other disturbance (Vose and White 1987, Huffman and Moore 2004). A large proportion of an annual seed crop may be consumed by predispersal, chalcidoid parasites (Huffman 2002). No detailed information presently exists concerning postdispersal seed fate or rates of seed predation.

In this research I studied annual rates of $C$. fendleri flower, fruit, and seed production; ovule loss; and seed germination. My specific objectives were to determine the following: (1) relationships of stem size to fruit and seed

${ }^{1}$ Ecological Restoration Institute, Northern Arizona University, Flagstaff, AZ 86011-5017. 
production, (2) magnitude and relative importance of processes leading to ovule loss, and (3) seed dormancy characteristics and important seed germination cues.

\section{Methods}

\section{Study Site}

I studied C. fendleri seed production at the Fort Valley Experimental Forest about $10 \mathrm{~km}$ northwest of Flagstaff, Arizona. The area receives around $52 \mathrm{~cm}$ of precipitation annually with distinct dry periods in May and June. Precipitation falls in late summer as rain from monsoonal thunderstorms and in winter as snow. The study area was located from $2225 \mathrm{~m}$ to $2380 \mathrm{~m}$ above mean sea level. Aspect was generally southern, and topography was gentle with average slopes of approximately $5 \%-10 \%$. Soils were moderately deep clay loam, classified as Typic Argiborolls and Mollic Eutroboralfs, and developed on tertiary basalt (Miller et al. 1995).

Seed population studies were conducted within 3 nearly pure ponderosa pine management units ( $\sim 15$ ha each) undergoing ecological restoration treatments. Restoration treatments included overstory thinning and prescribed fire. Thinning was completed in 19981999. Overstory stand densities in the forest units were 140-242 trees $\cdot \mathrm{ha}^{-1}$ and basal area was approximately $15.6-22.3 \mathrm{~m}^{2} \cdot \mathrm{ha}^{-1}$ (Fulé et al. 2001). Prescribed burning was done in 2000 and 2001. Common understory species included grasses such as Arizona fescue (Festuca arizonica Vasey), mountain muhly (Muhlenbergia montana [Nutt.] A.S. Hitchc.), bottlebrush squirreltail (Elymus elymoides [Raf.] Swezey), and pine dropseed (Blepharoneuron tricholepis [Torr.] Nash); forbs such as lupine (Lupinus spp.), fleabane (Erigeron spp.), buckwheat (Eriogonum spp.), yarrow (Achillea millifolium L.), and pussytoes (Antennaria spp.); and shrubs such as C. fendleri and woods rose (Rosa woodsii Lindl.). Large mammalian herbivores present on the site included mule deer (Odocoileus hemionus) and Rocky Mountain elk (Cervus elaphus). Domestic livestock were excluded from the study site.

\section{Flower, Fruit, and Seed Production}

In early spring 1999, I located 60 C. fendleri shrubs (180 total) in each of the 3 forest units described above. Shrubs comprised 1 to many stems in a patch and patches were generally $<2 \mathrm{~m}$ in diameter. I randomly assigned 30 shrubs in each forest unit (90 shrubs total) to be protected from large herbivores. Shrubs were surrounded by wire mesh exclosures, $2 \times$ $2 \mathrm{~m}$ in area and $1.4 \mathrm{~m}$ in height. Flower, fruit, and seed production of $C$. fendleri stems were examined in 2000 and 2001 on $1-\mathrm{m}^{2}$ plots centered on these protected plants. Due to impacts of prescribed fire, implemented in association with forest restoration activities, I did not sample all plots in both years; sample sizes were 73 and 58 plots in 2000 and 2001, respectively.

Plots were examined for flowering stems in June of each year. Length, diameter, and age class were recorded for flowering stems found on these plots each year (Huffman and Moore 2003). In July I identified all stems with fruits. In 2000 all stems bearing fruit were sampled, but in 2001 fruit production was prolific and fruiting stems were randomly sampled at a rate of $50 \%$. For each sampled stem, number of fruits and dehisced receptacles were counted. To estimate seed production, fruits were surrounded with nylon mesh (mesh size $<2 \mathrm{~mm}$ ) "traps" that caught seeds as they were dispersed. In 2000 all stems bearing fruit were fitted with seed traps. In 2001 stems randomly selected for measurement were fitted with seed traps.

In late August of both sample years, seed trap contents (seeds, debris, and fruit remaining on stems) were collected and taken to the laboratory for analysis. Seeds collected from traps were separated from plant debris and counted. Seeds were classified as developed or undeveloped. Developed seeds were approximately $2 \mathrm{~mm}$ in diameter with smooth, full seed coats and were glossy brown in appearance. In contrast, undeveloped seeds were typically smaller than $2 \mathrm{~mm}$, flattened, and had wrinkled, yellowish seed coats.

\section{Seed Parasitism}

Developed seeds collected in traps were examined under a dissecting scope (10-20 power) for parasite emergence holes or other signs of damage. All developed seeds were dissected to determine embryo condition and presence of parasite larvae or pupae. A small sample $(n=10)$ of undeveloped seeds were also dissected. To identify seed parasites, I monitored (1999-2001) seeds collected from 
C. fendleri shrubs growing on microsites adjacent to the restoration units. Adult parasites emerging from seeds were captured and preserved in $70 \%$ isopropyl alcohol. Specimens were sent to Dr. Robert Zuparko at the California Academy of Science (CAS), San Francisco, California, and to the USDA Systematic Entomology Laboratory (SEL; specimens identified by E. Eric Grissell, Research Entomologist), Bethesda, Maryland, for identification. Data for predispersal seed parasitism in 2000 were presented in Huffman (2002).

\section{Seed Predation}

To obtain rates of postdispersal seed predation, I quantified removal of $C$. fendleri seeds (collected 1999) from experimental seed depots at the Fort Valley site in September 2000 and 2001. Seed predation transects, $250 \mathrm{~m}$ in length, were systematically established in the 3 forest units. Transects were located near C. fendleri plots and systematically oriented in directions that assured they remained within the forest restoration units (i.e., transects did not extend into adjacent forest areas). At 50-m intervals (5 points) along transects, seed depots were established and C. fendleri seeds were placed on substrate-filled petri dishes. To investigate how seed predation varied with substrate, 2 dishes at each seed depot were filled with charred forest floor substrate and the other 2 with unburned ponderosa pine needles. Charred forest floor substrate was collected on-site from forest units that had been burned with prescribed fire. Ten C. fendleri seeds were placed on the substrate surface of each dish. In 2001 an additional dish of each substrate was added to randomly selected points along each transect, and sunflower (Helianthus sp.) seeds were placed on these. Sunflower seeds were added to indicate seed predator activity and relative preference for $C$. fendleri seeds; sunflower seeds were presumed to be preferred by many generalist seed predators (C. Chambers, School of Forestry, Northern Arizona University, personal communication).

Seed depots were left in place for 8-10 days. At collection, petri dishes were covered and transported to the laboratory for analysis. Seeds remaining in dishes were sieved from substrate and counted to determine the number removed at depots.

\section{Seed Germination}

To provide a general characterization of $C$. fendleri seed germination traits, seeds were collected from 4 sites near Flagstaff, Arizona: (1) Bear Jaw Canyon (BJ), (2) Dutton Hill (DH), (3) Fort Valley (FV), and (4) Obsidian Tank (OT). The sites were separated by at least $21 \mathrm{~km}$ and ranged in elevation from $2219 \mathrm{~m}$ to $2306 \mathrm{~m}$. Two of the sites (DH and OT) had experienced wildfires between 1975 and 1985, and no overstory trees were present. One site (BJ) had an open overstory of ponderosa pine as a result of thinning and prescribed fire in the mid-1980s. Seeds collected at the Fort Valley site were found in areas of open overstory conditions near a main road and hiking trail outside the experimental forest units used in seed production studies. Ceanothus fendleri capsules were collected from each of the 4 sites in late August 2001 just prior to natural dehiscence and seed dispersal. Capsules from at least 5 shrub patches per site were collected and stored in paper bags until processed. In the laboratory, seeds were separated from capsules by gently grinding with a mortar and pestle. Ten seeds were separated from each of the 4 collections and randomly assigned to 1 treatment of a 6 (temperature) $\times 2$ (cold stratification) factorial design . Additionally, because parasite infestation is difficult to determine from seed appearance (Huffman 2002), 5 samples of 9-17 seeds each were separated from each of the 4 seed collection sites and dissected as previously described. Rates of parasitism and filled seed were recorded. Temperatures tested were the following: no heat, $50^{\circ} \mathrm{C}, 70^{\circ} \mathrm{C}, 90^{\circ} \mathrm{C}, 110^{\circ} \mathrm{C}$, and $130^{\circ} \mathrm{C}$. Seeds were heated for 10 minutes in an electric drying oven following the procedures described above. Each treatment was replicated 3 times per site. Treatment replication was defined as separate application of heat. Seeds were then either cold-stratified or left unstratified. Unstratified seeds were placed on moistened filter paper in petri dishes and germinated in a controlled incubation chamber (Percival Scientific, Inc., model 1500). Day length and temperature in the chamber were set at 14 hours and $30^{\circ} \mathrm{C}$, respectively. Fullspectrum, fluorescent lighting was provided during day periods. Night length and temperature were 10 hours and $20^{\circ} \mathrm{C}$, respectively. Seeds were examined approximately every 2 days until germination was completed (about 
24 days). Germination was defined as successful if radicals extended beyond the seed coat by at least $2 \mathrm{~mm}$. Stratified seeds were placed between moistened filter papers in petri dishes and allowed to imbibe water at room temperature (about $20^{\circ} \mathrm{C}$ ) for 24 hours. Petri dishes were then sealed in black plastic and placed in a cooler at approximately $4^{\circ} \mathrm{C}$ for 60 days. After this period, unstratified seeds were germinated as described above.

Germinability of undeveloped seeds was tested by separating 100 seeds from each of the Dutton Hill and Fort Valley collections. Lots of 50 seeds each were randomly assigned to either heat treatment $\left(90^{\circ} \mathrm{C}\right.$ ) or control (no heat). Germination tests followed the procedures described above.

\section{Data Analysis}

Percentage of stems that produced flowers was calculated for individual plots, and means were reported for all sampled plots pooled among the 3 overstory units. Chi-square tests were used to analyze distributions of fruiting stem sizes versus sizes of all stems in the population (i.e., stems on all sampled plots; Devore and Peck 1986). Normality of stem size distributions was assessed using normal probability plots. Stem length and diameter data were separated into 13 classes for analysis. A probability level of 0.05 was used to determine significant deviation from chi-square critical values.

Linear regression was used to examine relationships between fruit and seed production in 2001 and between stem length and diameter. Data were natural-log transformed when residual plots showed increasing variance with increasing values of the independent variable. Relationships were considered significant when $P<0.05$.

Mann-Whitney nonparametric tests were used to test differences in number of seeds removed from charred forest floor and unburned pine litter substrates in the postdispersal seed predation experiments. A probability level of 0.05 was used for tests of statistical significance.

Analysis of variance (ANOVA) was used to test for main effects $(P<0.05)$ of cold stratification (2 levels) and temperature (6 levels) factors on seed germination. Collection site was used as a blocking factor in the ANOVA model. Seed germination values were square-root, arcsine transformed to improve normality and homogeneity of variances. When main effects were found, Bonferroni post hoc tests were used to compare mean differences between factor levels (Kuehl 1994). Means were not adjusted for parasitism or unfilled seeds, although rates of soundness obtained from dissections were considered in interpretation of results.

\section{REsUlts}

Flower, Fruit, and

Seed Production

Ceanothus fendleri flower and fruit production generally increased over the 2 years of sampling. Mean percentage of stems that produced flowers was $19 \%\left(s_{\bar{x}}=3.4\right)$ and $30 \%\left(s_{\bar{x}}\right.$ $=5.0)$ in 2000 and 2001, respectively. For fecund stems, mean number of fruit produced per stem was $7.4\left(s_{\bar{x}}=3.2\right)$ in 2000 and 39.4 $\left(s_{\bar{x}}=7.4\right)$ in 2001. Chi-square goodness-of-fit tests indicated that observed fruiting stems were large relative to their expected sizes (Fig. 1). No stems $<20 \mathrm{~cm}$ in length were observed bearing fruit, although these sizes represented $11 \%$ of the total stems on plots. Similarly, no stems $<2.5 \mathrm{~mm}$ in basal diameter fruited, yet they represented $23 \%$ of the population. Although fruiting stems were relatively large, number of fruits produced per stem was not linearly related to stem length $(P>0.05)$. A very weak positive relationship $\left(r^{2}=0.06, P=0.02\right)$ existed between fruit production and stem diameter.

Patterns of seed production followed those for fruiting. In 2000, seed-bearing stems produced $14.4\left(s_{\bar{x}}=7.8\right)$ total seeds per stem on average. This represented a $35 \%$ ovule loss from the potential number of seeds when based on 3 ovules per fruit (Kearney and Peebles 1964; Table 1). Of the total seeds produced in 2000 , the majority were undeveloped (Table 2). Dissections of undeveloped seeds showed either no embryo present (i.e., unfilled seed) or small flattened embryos. The other source of substantial ovule loss in 2000 was parasitism by a chalcidoid wasp (Eurytomidae: Eurytoma squamosa Bugbee; Table 2). Parasitized seeds from which wasps had emerged were hollow. On average $1.9\left(s_{\bar{x}}=1.6\right)$ sound seeds were produced per stem in 2000, an amount that represented a predispersal ovule loss of 91.4\% based on seed production potential (Table 1). 

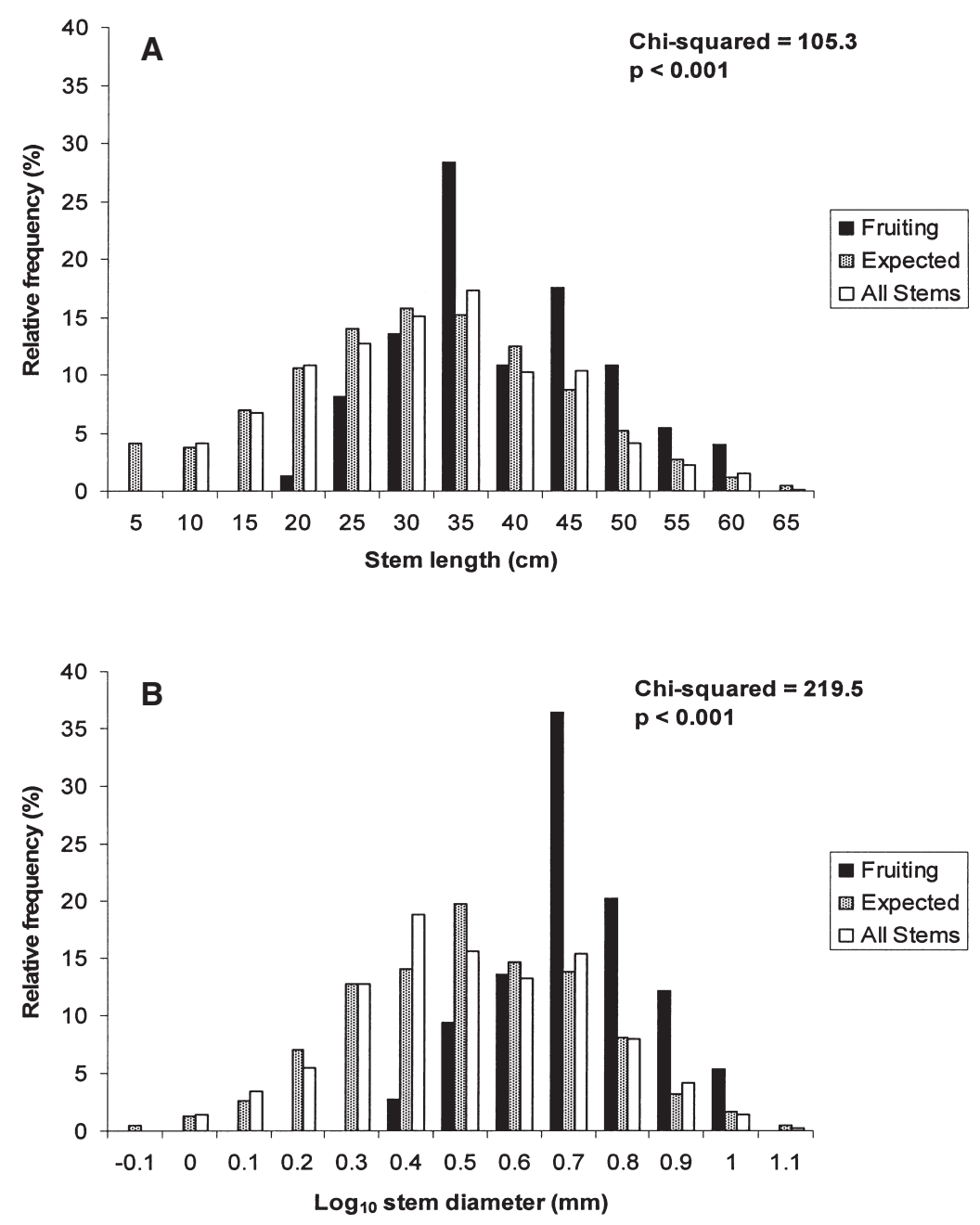

Fig. 1. Chi-square tests of observed versus expected (A) length and (B) diameter for fruiting stems of Ceanothus fendleri.

In 2001 an average of $90.9\left(s_{\bar{x}}=26.8\right)$ total seeds per stem were produced. Similar to patterns in 2000, this number represented a $23 \%$ ovule loss from the potential seed number based on fruit production (Table 1). As in 2000, parasitism and failure to develop were major sources of ovule loss in 2001 (Table 2). Number of sound seeds produced in 2001 averaged 34.6 per stem $\left(s_{\bar{x}}=11.6\right)$, an amount that represented a predispersal loss of $70.7 \%$ based on seed production potential (Table 1).

Similar to fruit production, linear regression analysis showed no linear $(P>0.05)$ relationship between total numbers of seeds produced and stem length. A weak $\left(r^{2}=0.09, P\right.$
$=0.005)$ positive relationship was found between number of seeds produced per stem and stem diameter.

\section{Post-dispersal Seed Predation}

In 2000 few C. fendleri seeds were removed from seed depots in the 3 experimental restoration units. I found no significant $(P>$ $0.05)$ difference in counts of seeds removed from charred forest floor or unburned litter substrate (Table 3). Seed removal averaged $1.0 \%\left(s_{\bar{x}}=1.0\right)$ across all samples.

In 2001 significantly $(P<0.05)$ more seeds were removed from dishes containing charred 
TABLE 1. Mean number of Ceanothus fendleri ovules per stem $\left(s_{\bar{x}}\right.$ in parentheses). Also shown are predisperal and cumulative losses as a percentage of the potential number of seeds.

\begin{tabular}{llrr}
\hline Stage & Fate & 2000 & 2001 \\
\hline Predispersal & Potential $^{1}$ & $22.2(9.6)$ & $118.2(22.2)$ \\
& Produced $^{2}$ & $14.4(7.8)$ & $90.9(26.8)$ \\
Postdispersal & Filled $^{3}$ & $1.9(1.6)$ & $34.6(11.6)$ \\
Predispersal loss $(\%)$ & Escaped $^{4}$ & 1.9 & $26.2-34.0$ \\
Cumulative loss $(\%)$ & & 91.4 & 70.7 \\
\hline
\end{tabular}

${ }^{1}$ Number of fruits per stem $\times 3$ potential ovules per fruit

${ }^{2}$ Number of seeds caught per stem in traps. Values include undeveloped, parasitized, hollow, and filled seeds.

${ }^{3}$ Number of seeds per stem with apparently healthy embryos, based on seed dissections

${ }^{4}$ Number of filled seeds that would hypothetically escape postdispersal predation. Values are based on removal rates from field studies. Predation in 2000 $(0 \%-2 \%)$ did not appreciably affect predispersal loss at the statistical precision shown.

forest floor substrate than those with unburned litter (Table 3). On charred forest floor substrate, nearly one-fourth of $C$. fendleri seeds were removed whereas removal on unburned litter was less than 3\%. Discarded C. fendleri seed coats at depots suggested that seed predators, probably rodents, immediately consumed seeds as they found them. Although low sample size made sunflower seed removal patterns difficult to assess, trends appeared to be similar to those observed for C. fendleri. No sunflower seeds remained in any dish containing charred forest floor substrate whereas about one-third of the seeds escaped predation in dishes containing unburned litter (Table 3).

\section{Seed Germination}

Cold stratification did not affect $C$. fendleri germination, but pregermination heat treatment was a significant factor in the ANOVA model. No interaction was found between stratification and heat treatment.

Seeds exposed to $70^{\circ} \mathrm{C}$ and $90^{\circ} \mathrm{C}$ for 10 minutes had significantly greater germination than seeds receiving the no-heat treatment and those exposed to $50^{\circ} \mathrm{C}, 110^{\circ} \mathrm{C}$, or $130^{\circ} \mathrm{C}$ (Fig. 2). Not all seeds displayed innate dormancy, and $13 \%$ of seeds in the no-heat treatment germinated. No seeds exposed to $130^{\circ} \mathrm{C}$ germinated. Further, seeds classified as "undeveloped" in production studies did not germinate regardless of whether or not they were subjected to heat treatment.

Dissection of random seed samples showed dramatically different conditions between the 4 collection sites (Table 4). For example, parasitized and otherwise unfilled seeds comprised $57 \%-84 \%$ of the total number of seeds from BJ and OT sites. In contrast, over $75 \%$ of the seeds
TABLE 2. Fate of Ceanothus fendleri ovules. Shown is mean percentage of total seeds produced per fecund stem ( $s$ in parentheses).

\begin{tabular}{lcccr}
\hline & \multicolumn{4}{c}{ Ovule fate (\% of total seeds per stem) } \\
\cline { 2 - 5 } Year & Undeveloped & Parasitized & Unfilled & \multicolumn{1}{c}{ Sound } \\
\hline 2000 & $64.4(13.2)$ & $28.2(11.8)$ & $0.3(0.3)$ & $7.1(4.5)$ \\
2001 & $71.6(25.2)$ & $11.0(22.3)$ & $0.6(0.2)$ & $25.1(2.7)$ \\
\hline
\end{tabular}

from $\mathrm{DH}$ and FV sites were sound. Estimates of germination percentage adjusted for sound seed were $17 \%, 3 \%, 41 \%, 50 \% 27 \%$, and $0 \%$ for no heat, $50^{\circ} \mathrm{C}, 70^{\circ} \mathrm{C}, 90^{\circ} \mathrm{C}, 110^{\circ} \mathrm{C}$, and $130^{\circ} \mathrm{C}$, respectively.

\section{Discussion}

\section{Factors Affecting} Seed Production

Production of C. fendleri fruits and seeds increased by more than 1 order of magnitude from 2000 to 2001 . These seed production patterns may have resulted from increases in stem size and leaf area developing over time since overstory thinning in 1998-1999. In addition, variation in seed production is also driven by genetic and climatic factors. Variability in fruit production has been linked to precipitation for other species of Ceanothus in chaparral ecosystems (Keeley 1977, Keeley 1987, Zammit and Zedler 1992). In my study, the year 2000 was droughty during the growing season $(63 \%$ of long-term average January-September [Western Regional Climate Center 2003]) whereas precipitation in 2001 was closer $(91 \%)$ to the long-term average for the site. Thus, variation in seed production was likely a response to combined factors of 
TABLE 3. Mean percent removal of Ceanothus fendleri seeds $\left(s_{\bar{x}}\right.$ in parentheses) from charred forest floor and unburned ponderosa pine litter substrates at seed depots in 2000 and 2001.

\begin{tabular}{lcccc}
\hline \multirow{2}{*}{ Species } & \multicolumn{2}{c}{2000} & & \multicolumn{2}{c}{2001} \\
\cline { 2 - 5 } & Charred & Litter & Charred & Litter \\
\hline C. fendleri $(n=15)$ & $2.0(2.0)$ & $0.0(0.0)$ & $24.3^{1}(6.3)$ & $2.7(1.2)$ \\
Helianthus $^{2}(n=3)$ & - & - & $100.0(0.0)$ & $66.7(33.3)$ \\
\hline
\end{tabular}

$1_{1}$ Mean C. fendleri seed removal significantly $(P<0.01)$ greater on charred forest floor than on unburned litter in 2001.

${ }^{2}$ Sunflower seeds were not used for removal experiment in 2000.

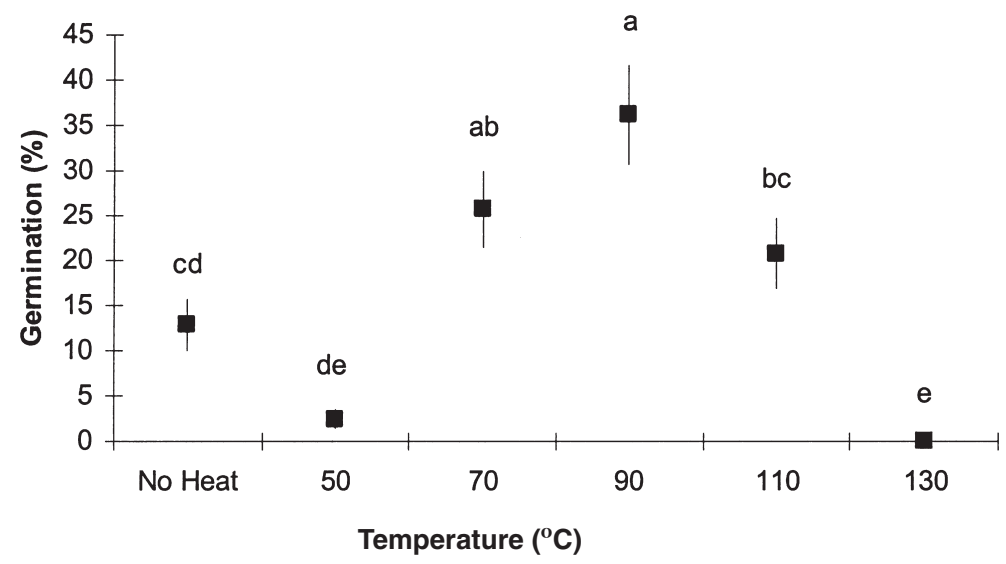

Fig. 2. Effect of temperature on Ceanothus fendleri seed germination. Seeds were exposed to the given temperatures for 10 minutes. Means are for cold-stratified and unstratified seeds combined and bars represent standard errors. Values are not adjusted for unfilled and parasitized seeds. Similar letters indicate statistically similar means at $\alpha=0.05$.

growing season precipitation and forest thinning.

I found that fruit and seed production was positively, but weakly related to $C$. fendleri stem size. Similarly, Zammit and Zedler (1992) found that shrub size was the primary determinant of seed production for desert ceanothus (C. greggii Gray). Greater numbers of large stems in C. fendleri populations will likely increase the potential for population growth following ecological restoration treatments.

\section{Ovule and Seed Losses}

Differences between potential (i.e., fruiting) and actual seed production (i.e., both undeveloped and developed seeds) suggested that about 1 C. fendleri ovule per fruit failed to develop (33\% failure). Ovules are commonly lost as a result of herbivory and predispersal predation (Furniss et al. 1978). Otherwise, ovule losses are thought to be linked to deficient pollination, resource limitation, or both (Stephenson
1981). During field measurements, I observed fruit damage that appeared to be consistent with predation by invertebrates, but I was not able to directly measure these ovule losses. Predispersal parasitism was variably important in further reducing the number of viable seeds. Rates of filled seed and parasitism for seeds trapped in 2000 were presented in Huffman (2002). The chalcidoid wasp, Eurytoma squamosa, was the only predispersal seed parasite found. Parasitic wasps of the Eurytoma genus are known to feed on seeds of several Ceanothus species and members of the Rhamnaceae family (Bugbee 1967, Bugbee 1971, Furniss and Krebill 1972, Furniss et al. 1978, Huffman 2002, Michael Gates, Systematic Entomology Laboratory, personal communication).

Incomplete seed ripening was another consistently important source of predispersal seed loss in both study years. Dissection and germination tests confirmed that seeds classified as undeveloped were not viable. Rates of annual 
TABLE 4. Condition of Ceanothus fendleri seeds used for germination experiments.

\begin{tabular}{lccc}
\hline & \multicolumn{3}{c}{ Seed Condition (\%) } \\
\cline { 2 - 4 } Site & Unfilled & Parasitized & Filled \\
\hline Bear Jaw (BJ) & 44.2 & 12.9 & 42.9 \\
Dutton Hill (DH) & 1.3 & 11.6 & 87.1 \\
Fort Valley (FV) & 21.0 & 1.2 & 77.8 \\
Obsidian Tank (OT) & 60.2 & 23.8 & 16.0 \\
\hline
\end{tabular}

seed abortion for other Ceanothus species range from $33 \%$ to $86 \%$ and may vary with resource availability, carbohydrate reserves, or plant age (Keeley 1977, Furniss et al. 1978, Zammit and Zedler 1992).

Postdispersal seed predation was a variably (2\%-24\% of dispersed seeds) important source of seed loss. Although I did not attempt to determine identities of seed predators, discarded seed coats left at depots suggested that rodents were responsible for some predation that resulted in seed mortality. Rodents such as Tamias cinericolis, T. dorsalis, Peromyscus maniculatus, and Neotoma spp. are common in these forests and have been implicated in high rates of ponderosa pine seed predation $(80 \%)$ on similar sites (Compton 2004). Further, my results suggest that seeds dispersed onto fine substrate such as charred forest floor may be easier for seed predators to locate than those on coarse substrate such as pine litter. Similar effects have been reported for Ceanothus in chaparral ecosystems where vertebrate seed predators had difficulty locating seeds buried beneath plant litter (Mills and Kummerow 1989). My results suggest that $C$. fendleri seeds may be an important resource in food webs of ponderosa pine forests in northern Arizona. It follows that intense herbivory (e.g., by Rocky Mountain elk) that leads to substantial reductions in flower and seed production may affect energy flow and species distribution in these ecosystems.

\section{Seed Germination}

Seed germination results suggested that $C$. fendleri utilizes a dormant-seed regeneration strategy. Many Ceanothus species require heat to allow opening of seed coats, although a few show adverse response to heating (Hadley 1961, Quick and Quick 1961, Gratkowski 1974, Reed 1974, Keeley 1977, Conard et al. 1985). In other ecosystems Ceanothus seeds are thought to remain viable in soil for decades (Gratkowski
1974, Keeley 1977). Longevity of C. fendleri seeds under field conditions is not known, although its seeds can remain viable in dry storage for $>40$ years (Huffman unpublished data). Seed dormancy may confer a reproductive advantage when fire both stimulates germination and increases the abundance of safe sites for seedling establishment (Keeley 1977, Huffman and Moore 2004). In this study I found that germination of seeds that received no heat treatment was $13 \%$. Further reproductive advantage may be gained from this bethedging strategy wherein seed cohorts comprise both dormant and nondormant seeds. Such a strategy may allow persistence of $C$. fendleri populations in understory environments that are temporally variable in terms of disturbance and safe site availability.

\section{Implications}

Results of this study suggest that management activities encouraging development and maintenance of large stems are likely to increase seed production of C. fendleri. Such activities include overstory thinning, prescribed fire, and protection from large herbivores (Huffman 2003, Huffman and Moore 2003, Huffman and Moore 2004). However, climatic variability is likely to affect annual production, and prediction of population trends should include several years of monitoring. In some years a substantial percentage of developed seeds may be lost to predispersal parasites or postdispersal seed predators, and this may lead to short-term limitations on regeneration (Andersen 1989). Seed dissection and Xray analysis could help determine proportion of infested seed.

Seed dormancy may allow accumulation of C. fendleri seeds in soil seed banks, which in turn may facilitate population recovery after disturbance. Similarly, prescribed fires of low severity may increase $C$. fendleri abundance. Ecologists and land managers interested in $C$. fendleri seed banks can apply heat treatments to samples in order to stimulate viable seeds. Heat scarification of field-collected seeds will likely increase germination success.

\section{ACKNOWLEDGMENTS}

M.M. Moore, W.W. Covington, T.E. Kolb, T.D. Sisk, and 2 anonymous reviewers provided valuable comments on early drafts of 
this manuscript. A. Fields, T. Hudelson, and students and staff of the Ecological Restoration Institute at Northern Arizona University assisted in field data collection and laboratory work. This project was funded by USDA Forest Service, Rocky Mountain Research Station and Northern Arizona University (School of Forestry) Research Joint Venture Agreement RMRS-99167-RJVA.

\section{Literature Cited}

Andersen, A.N. 1989. How important is seed predation to recruitment in stable populations of long-lived perennials? Oecologia 81:310-315.

Bugbee, R.E. 1967. Revision of chalcid wasps of genus Eurytoma in America, north of Mexico. Proceedings of the United States National Museum 118:433-532.

1971. A new species of Arizona Eurytoma phytophagous in Ceanothus greggii seeds. Journal of the Kansas Entomological Society 44:111-112.

Compton, L.E. 2004. Ponderosa pine dispersal and recruitment: the role of seed-caching rodents. Doctoral dissertation, Northern Arizona University, Flagstaff.

Conard, S.G., A.E. Jaramillo, K. Cromack Jr., and S. Rose. 1985. The role of the genus Ceanothus in western forest ecosystems. USDA Forest Service General Technical Report PNW-182.

Devore, J., And R. Peck. 1986. Statistics-the exploration and analysis of data. West Publishing Co., St. Paul, MN.

EpPLE, A.O. 1995. A field guide to the plants of Arizona. Falcon Press, Helena.

Fulé, P.Z., C. McHugh, T.A. Heinlein, and W.W. CovINGTON. 2001. Potential fire behavior is reduced following forest restoration treatments. Pages 28-35 in R.K. Vance, C.B. Edminster, W.W. Covington, and J.A. Blake, compilers, Ponderosa pine ecosystems restoration and conservation: steps toward stewardship. USDA Forest Service Proceedings RMRS-P-22.

Furniss, M.M., AND R.G. KrebiLL. 1972. Insects and diseases of shrubs on western big game ranges. Pages 218-226 in C.M. McKell, J.P. Blaisdell, and J.R. Goodin, technical editors, Wildland shrubs-their biology and utilization. USDA Forest Service General Technical Report INT-I.

Furniss, M.M., T.A. LEEGE, AND R.J. NASKaLI. 1978. Insects that reduce redstem ceanothus seed production in Idaho. Pages 355-358 in D.N. Hyder, editor, Proceedings of the First International Rangeland Congress. Society for Range Management, Denver, CO.

GratKowsKi, H. 1974. Origin of mountain whitethorn brushfields on burns and cuttings in Pacific Northwest forests. Western Society of Weed Science Proceedings 27:5-8.

Hadley, E.B. 1961. Influence of temperature and other factors on Ceanothus megacarpus seed germination. Madroño 16:132-138.

Huffman, D.W. 2002. A seed chalcid (Eurytoma squamosa Bugbee) parasitizes seeds of Fendler ceanothus (Ceanothus fendleri Gray) in a ponderosa pine forest of Arizona. Western North American Naturalist 62: 474-478.

Huffman, D.W. 2003. Population ecology of Fendler ceanothus: responses to herbivory and forest restoration treatments. Doctoral dissertation, Northern Arizona University, Flagstaff.

Huffman, D.W., and M.M. Moore. 2003. Ungulate herbivory on buckbrush in an Arizona ponderosa pine forest. Journal of Range Management 56:358-363.

2004. Responses of Fendler ceanothus to overstory thinning, prescribed fire, and drought in an Arizona ponderosa pine forest. Forest Ecology and Management 198:105-115.

Kearney, T.H., And R.H. Peebles. 1964. Arizona flora. University of California Press, Los Angeles.

KeELEY, J.E. 1977. Seed production, seed populations in soil, and seedling production after fire for two congeneric pairs of sprouting and nonsprouting chaparral shrubs. Ecology 58:820-829.

1987. Fruit production patterns in the chaparral shrub Ceanothus crassifolius. Madroño 34:273-282.

Krishnan, S. 1989. Propagation of four native drought tolerant shrubs-Ceanothus spp. and Sherpherdia spp. Master's thesis, Colorado State University, Fort Collins.

KuEHL, R.O. 1994. Statistical principles of research design and analysis. Wadsworth Publishing Co., Belmont.

Miller, G., N. Ambros, P. Boness, D. Reyher, G. Robertson, K. Scalzone, R. Steinke, and T. Subirge. 1995. Terrestrial ecosystem survey of the Coconino National Forest. USDA Forest Service, Southwestern Region, Albuquerque, NM.

Mills, J.N., AND J. Kummerow. 1989. Herbivores, seed predators, and chaparral succession. Pages 49-53 in S.C. Keeley, editor, The California chaparral-paradigms reexamined. Science Series No. 34. Natural History Museum, Los Angeles, CA.

Quick, C.R., AND A.S. Quick. 1961. Germination of Ceanothus seeds. Madroño 16:23-31.

ReED, M.J. 1974. Ceanothus L. Ceanothus. Pages 284-290 in C.S. Schopmeyer, technical coordinator, Seeds of woody plants in the United States. USDA Forest Service Handbook No. 450.

STEPHENSON, A.G. 1981. Flower and fruit abortion: proximate causes and ultimate functions. Annual Review of Ecology and Systematics 12:253-279.

STORY, M.T. 1974. Nitrogen fixation by Ceanothus fendleri and Lupinus argenteus as a function of parent material and vegetal cover. Master's thesis, University of Arizona, Tucson.

Vose, J.M., AND A.S. White. 1987. Process of understory seedling recruitment 1 year after prescribed fire in an Arizona ponderosa pine community. Canadian Journal of Botany 65:2280-2290.

Western Regional Climate Center. 2003. Historical climate data. Available from: http://www.wrcc.dri.edu

Zammit, C.A., And P.H. Zedler. 1992. Size structure and seed production in even-aged populations of Ceanothus greggii in mixed chaparral. Journal of Ecology 81:499-511. 